\title{
Drug-Induced Aplastic Anemia
}

National Cancer Institute

\section{Source}

National Cancer Institute. Drug-Induced Aplastic Anemia. NCI Thesaurus. Code C35343.

A state of bone marrow suppression and failure that is caused by a cytotoxic or adverse immunologic response to a drug treatment, leading to a failure of production of red blood cells, white cells and platelets. 